\title{
Control Algorithm of Precision Machining
}

\author{
Xiongfei Chi* \\ Ordos Vocational College, Inner Mongolia Autonomous Region, China
}

\begin{abstract}
Due to more and more private customized non-standard design and precision manufacturing, as well as strict requirements for green environmental protection and sustainable economic development mode, it is challenging to realize the synchronous meeting of energy-saving optimization requirements in the processing process of high-precision workpiece. A new semi-automatic machining optimization system is proposed in this paper. The system is based on the high-precision 3D computer files of the workpiece to be processed and the laser thermophysical system. At the same time, the processing parameters are optimized based on the high-precision algorithm. The innovative contents of the high-precision optimization system include: (1) reciprocating fast high-frequency program design. Its single cycle task is: "core data acquisition, data in-depth analysis / machining precision refinement, key machining parameters recalibration", in order to maximize the process adaptability of the optimization system designed in this study in the highprecision machining process of different types of workpieces. (2) A new green energy-saving and environmental protection model, using primary chemical degreasing and laser derusting processing to get the most accurate $3 \mathrm{D}$ scanning files of parts waiting for processing, minimize the process error, so as to maximize the material and energy efficiency. In the calculation of the energy model, the most scientific consumption of coolant is considered.
\end{abstract}

\section{Research layout}

CNC processing is characterized by fast and large batch of non-standard private customization and small batch and large amount of green remanufacturing orders of maintenance nature. At the same time, the manufacturing and maintenance process needs to meet the stringent national standards of energy conservation and emission reduction and minimum consumables. Of course, it also needs to meet the requirements of timeliness.

The processing upper limit temperature of non-standard alloy, new temperature sensitive material and other special materials is considered, and priority should be given to ensure that the processing upper limit temperature is not exceeded.

\footnotetext{
* Corresponding author:279245150@qq.com
} 
Table 1. Shortcomings of existing high precision control algorithms.

\begin{tabular}{|c|c|}
\hline Features & Brief introduction \\
\hline Lack of coolant research & $\begin{array}{c}\text { There is no systematic algorithm for the scientific } \\
\text { and appropriate amount of coolant. }\end{array}$ \\
\hline Fast response of energy consumption & $\begin{array}{c}\text { Real time monitoring of heat, rapid response to } \\
\text { feed rate and coolant consumption rate, } \\
\text { continuous monitoring of actual temperature and } \\
\text { dissipated energy changes after response. }\end{array}$ \\
\hline Nhen dealing with the tasks in the highest \\
priority queue, even if it is very urgent, it is still \\
necessary to shut down the long-running \\
equipment for cooling. In order to prevent the \\
key parts overheating danger caused by circuit \\
aging or integrated circuit board electronic \\
components solder joint loose and electronic \\
components overheating failure.
\end{tabular}

\subsection{Analysis of existing research background}

\subsubsection{Forced transformation of green economy development mode}

Worldwide, energy conservation and environmental protection regulations and incentive policies have been promulgated, forcing high-precision high-end manufacturing industry to comprehensively upgrade and transform to green energy-saving and economic manufacturing mode ${ }^{[1]}$ (stark et al., 2017).

\subsubsection{Priority scheduling, self adaptation and self alignment algorithm}

Due to the rapid change of market demand, it is very natural for the batch priority of production and processing to change dynamically. As a profit-making enterprise, the production object with the highest profit and the most urgent time needs to be treated as the highest priority in the scheduling queue ${ }^{[2,3]}$ ( $\mathrm{Li}$ and McMahon, 2007; Wang et al., 2015).

Due to the systematic integration, some simple self-learning programs can be implemented in the chipset to perform self-adapting and self-aligning algorithms.

\subsection{The structure diagram of this study}

The content of this study can be organized as shown in the Figure 1 below:

- First of all, it is necessary to ensure that the processing details and special processing parameters specified in the user's purchase and sale contract are fully met.

- Pretreatment of the workpiece to be processed. Including: chemical degreasing, laser derusting, abrasive belt removing fatigue layer, ultrasonic cleaning and drying.

- Reverse design engineering: high precision dense point cloud CT scanning, combined with pre estimated original workpiece design drawings, comprehensive consideration of the use performance after processing, to make high-precision 3D target workpiece drawings.

- Preliminary processing design, rough estimation of various process parameters.

- Precision machining, running dynamic calibration, coolant pressure control and energy analysis program.

In the preliminary processing design stage, the rough estimation of various process parameters must have the subsequent process effect deduction. Because it must be ensured 
that after the process is executed, the effect will not cause special parameter values exceeding the upper limit of user calibration. That is to say, we must ensure that the technological terms in the purchase and sale contract are met all the time.

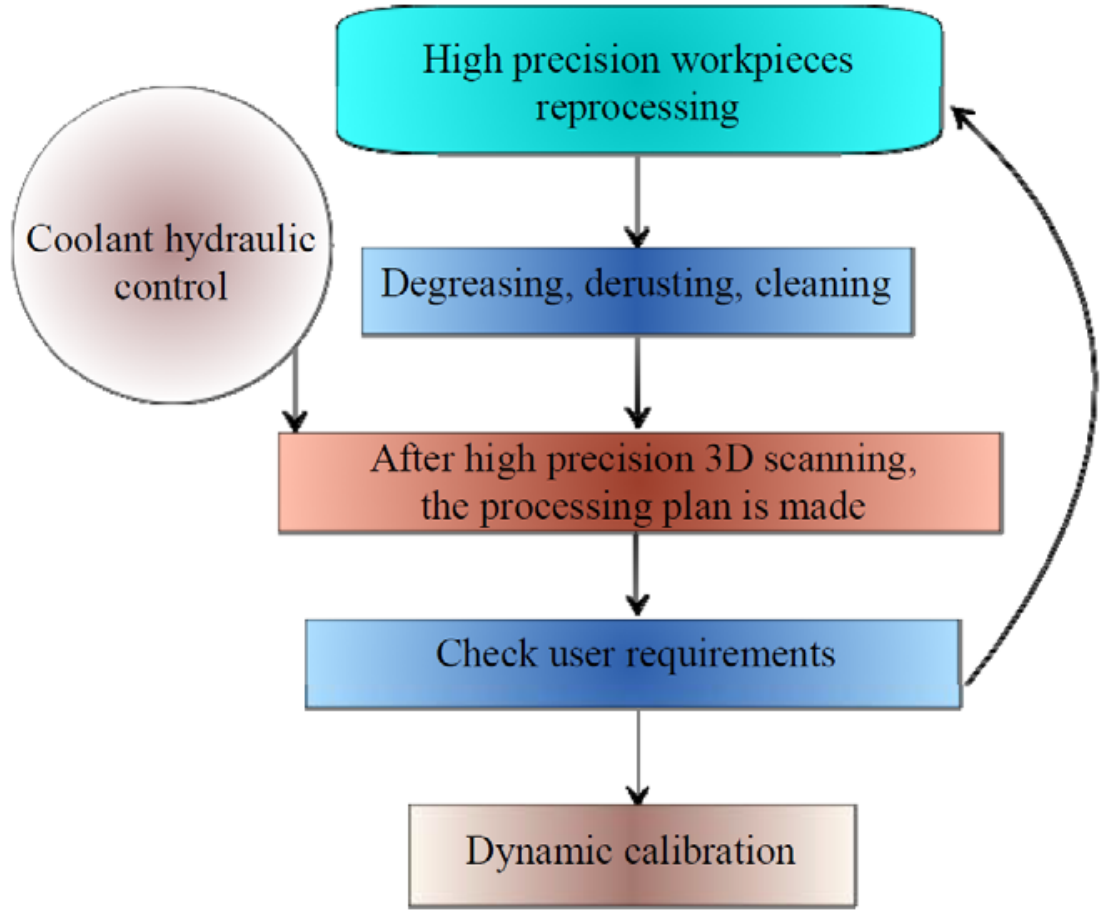

Fig. 1. Sketch of high precision machining system.

\section{Algorithm core formula}

From the input of initial key parameters, the import of high-precision 3D model, the import of user requirements, to the operation of high-precision self calibration machining program, each link has detailed precision design.

\subsection{User precision requirements: manual input or direct import of electronic documents}

The user's precise requirements may be in the form of audio file, video file, word format, TXT format, picture format, etc. Therefore, the technical details involved here include: Audio character recognition, image information intelligent extraction, dynamic video information extraction and other key technologies. If the extraction fails, the key information is manually inputted by the staff.

\subsection{Algorithm core}

$$
\left\{\begin{array}{l}
\mathrm{e}_{\text {workpiece }} \geq \mathrm{e}_{\text {Friction }} \Rightarrow \Delta H>0 \\
\mathrm{e}_{\text {workpiece }}<\mathrm{e}_{\text {Friction }} \Rightarrow \Delta H \leq 0
\end{array}\right.
$$


Where $\mathrm{e}_{\text {workpiece }}$ - means the measured energy increment of the workpiece. Because of position error and measuring equipment error, two groups of infrared testing instruments need to focus on one measuring point at the same time for error correction.

The $\mathrm{e}_{\text {Friction } ~}$ means the value of the work done by the precision machining head on the workpiece. Because of position error and measuring equipment error, two groups of infrared testing instruments need to focus on one measuring point at the same time for error correction.

The $\Delta \mathrm{H}_{-}$means the change of liquid pressure of coolant. When the temperature increases rapidly, it is necessary to increase the coolant flow rate to control the temperature in the normal range, and the value of $\Delta \mathrm{H}$ is greater than zero. On the contrary, the value of $\Delta \mathrm{H}$ is less than or equal to zero.

\section{Results and analysis}

This research puts forward a new design idea of high precision, energy saving and consumables saving machining system. Specifically, the design has the following characteristics.

-A closed-loop coolant consumption control algorithm based on energy online control is proposed.

-The fast measurement feedback of the dynamic response of feed rate and coolant flow rate. The machining accuracy and the transient heat value of the workpiece can be controlled without overheating or over machining.

-Based on the safety factors of expensive equipment, the necessary shutdown cooling for the equipment that has been performing processing tasks for a long time is carried out.

\section{Acknowledgement}

This research was carried out as a part of the Smarter and Robot projects which are supported by Ordos Vocational College. The authors acknowledge the funding agencies and industrial partners to support the research and industrial applications. The authors are also grateful to reviewers and editors for improving the quality of this paper.

\section{References}

1. Stark et al., 2017 R. Stark, G. Seliger, J. Bonvoisin Sustainable Manufacturing Springer (2017)

2. Li and McMahon, 2007 W.D. Li, C.A. McMahon A simulated annealing - based optimization approach for integrated process planning and scheduling Int. J. Comput. Integrated Manuf., 20 (1) (2007), pp. 80-95

3. Wang et al., 2015 S. Wang, X. Lu, X. Li, W.D. Li A systematic approach of process planning and scheduling optimization for sustainable machining J. Clean. Prod., 87 (2015), pp. 914-929

4. BinYang, GenbaoZhang, YanRan et al. Kinematic modeling and machining precision analysis of multi-axis CNC machine tools based on screw theory J. Mechanism and Machine Theory. Volume 140, (2019), pp. 538-552 